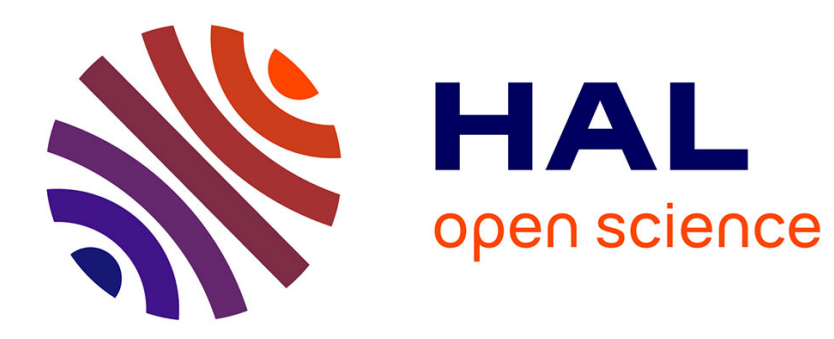

\title{
High Temperature Microplasticity of Fine-Grained Ceramics
}

\author{
A. Lakki, R. Schaller
}

\section{To cite this version:}

A. Lakki, R. Schaller. High Temperature Microplasticity of Fine-Grained Ceramics. Journal de Physique IV Proceedings, 1996, 06 (C8), pp.C8-331-C8-340. 10.1051/jp4:1996872 . jpa-00254680

\section{HAL Id: jpa-00254680 https://hal.science/jpa-00254680}

Submitted on 1 Jan 1996

HAL is a multi-disciplinary open access archive for the deposit and dissemination of scientific research documents, whether they are published or not. The documents may come from teaching and research institutions in France or abroad, or from public or private research centers.
L'archive ouverte pluridisciplinaire HAL, est destinée au dépôt et à la diffusion de documents scientifiques de niveau recherche, publiés ou non, émanant des établissements d'enseignement et de recherche français ou étrangers, des laboratoires publics ou privés. 
JOURNAL DE PHYSIQUE IV

Colloque C8, supplément au Journal de Physique III, Volume 6, décembre 1996

\title{
High Temperature Microplasticity of Fine-Grained Ceramics
}

\author{
A. Lakki(1) and R. Schaller \\ Ecole Polytechnique Fédérale de Lausanne, Institut de Génie Atomique, 1015 Lausanne, Switzerland
}

\begin{abstract}
Several fine-grained ceramics exhibit enhanced ductility or even structural superplasticity at high temperature. Grain boundaries play a dominant role in the deformation process of these materials which usually involves diffusion-accommodated grain boundary sliding. Sliding is either lubricated by an amorphous intergranular phase or takes place by glide and climb of grain boundary dislocations. At high temperature, anelastic deformation precedes plastic deformation and stems from the short range motion of lattice defects, such as dislocations and grain boundaries. The energy loss ("mechanical loss") associated with such motion can be measured by using the technique of mechanical spectroscopy. Moreover, at the onset of plasticity ("microplasticity"), long range irrecoverable motion of defects contributes to additional mechanical loss. Mechanical loss spectra may then give an insight into mechanisms operating at the transition between anelastic and plastic deformation. As an illustration, the spectra of three fine-grained ceramics $\left(\mathrm{Si}_{3} \mathrm{~N}_{4}, \mathrm{ZrO}_{2}, \mathrm{Al}_{2} \mathrm{O}_{3}\right)$ are presented. In all cases, anelastic relaxation phenomena (peak and background) have been observed at high temperature $(>1200 \mathrm{~K})$, bearing a close relation with creep behaviour. Their analysis permits to distinguish between different types of microstructural elements: bulk regions of amorphous intergranular phase at triple points, grain boundaries separated by a thin glassy film and "clean" grain boundaries.
\end{abstract}

\section{FINE-GRAINED CERAMICS: MICROSTRUCTURE AND PLASTIC DEFORMATION}

The high temperature mechanical properties such as toughness and creep resistance of fine-grained ceramics are controlled by their microstructure which determines the micromechanisms of plastic deformation. Several ceramics have been found to exhibit enhanced ductility or even structural superplasticity at high temperature (Table 1), for reviews see [1-11]. Although these ceramics are very different with regard to microstructure, physical and chemical properties, they share one common feature: all of them have a very fine grain size (of the order of a micron or less). Consequently, grain boundaries (GBs) play a dominant role in the high temperature deformation process of these materials. Effectively, a major component of high temperature deformation is attributed to diffusion-accommodated GB-sliding. Arguments for this are the low stress exponents (between 1 and 3, table 1), the retention of equiaxed grain form even after large deformation, the lack or scarcity of dislocations observed by TEM in crept specimens and the dependence of the creep rate on the grain size and on the GB morphology and chemistry.

GB-sliding is often lubricated by an amorphous intergranular phase, usually a $\mathrm{SiO}_{2}-$ or $\mathrm{YSiAlON}^{-}$ based glass, which originates in the use of sintering aids. This phase forms thin films (1-2nm thick) separating high energy GBs [12] and can also be found in the form of bulk glass pockets at triple grain junctions [13]. In the extreme case, the ceramic grains are embedded into a glass matrix (glass-ceramics). But even without any second phase ("clean" GBs), deformation by GB-sliding can take place, involving glide and climb of GB-dislocations. Finally, segregation and even precipitation of impurities or dopant elements to the GBs often occur, thus affecting the local chemistry and the mobility of GB-dislocations.

At high temperature, anelastic deformation precedes plastic deformation and stems from the short range motion of lattice defects, such as dislocations and grain boundaries. The energy loss ("mechanical loss") associated with such motion can be measured by using the technique of mechanical spectroscopy. Moreover, at the onset of plasticity, i.e. "microplasticity", long range irrecoverable motion of defects contributes to additional mechanical loss. The study of mechanical loss spectra may then give some insight into the mechanisms operating at the transition between anelastic and plastic deformation. In this range of deformations (at low stress and low temperature), creep is controlled by "interface-reaction" [14- 
15], which is of importance for the characterization of the materials (e.g. threshold-stresses) and the mechanisms of which are still not fully established. Moreover, thank to the low deformations involved, this technique permits to study grain sliding processes even in those materials where strain-enhanced grain growth would lead to a change of deformation mechanism in a conventional creep experiment.

As an illustration, the mechanical loss spectra of three types of fine-grained ceramics $\left(\mathrm{Si}_{3} \mathrm{~N}_{4}, \mathrm{ZrO}_{2}\right.$, $\mathrm{Al}_{2} \mathrm{O}_{3}$ ) are presented. In all three cases, anelastic relaxation phenomena were observed at high temperature $(>1200 \mathrm{~K})$, depending strongly on the GB-structure and being in close corretation with the creep behaviour.

Table 1: Selected fine-grained ceramics showing enhanced ductility or even superplastic deformability, in which GBsliding plays a major role (details and references can be found in many reviews, e.g. [1-11]). References are given in which mechanical loss measurements on identical or similar materials have been reported.

\begin{tabular}{|c|c|c|c|c|c|c|}
\hline $\begin{array}{c}\text { Ref. for } \\
\text { mech. spectr. }\end{array}$ & Material & GB-phase & $\begin{array}{l}\text { grain size } \\
{[\mu \mathrm{m}]}\end{array}$ & $\begin{array}{c}\mathrm{T} \\
{\left[{ }^{\circ} \mathrm{C}\right]} \\
\end{array}$ & $\begin{array}{c}\text { stress exp. } \\
\mathrm{n}\end{array}$ & $\begin{array}{c}\mathrm{H} \\
{[\mathrm{kJ} / \mathrm{mol}]}\end{array}$ \\
\hline \multirow[t]{2}{*}{ [16-18] } & $\begin{array}{l}\mathrm{ZrO}_{2} / 2 \mathrm{~mol}_{2} \mathrm{Y}_{2} \mathrm{O}_{3}(2 \mathrm{Y}-\mathrm{TZP}) \text { pure } \\
2 \mathrm{Y}-\mathrm{TZP}+910 \mathrm{ppmSiO} \mathrm{pmpurities}_{2}+\mathrm{imp} \text { puriel } \\
2 \mathrm{Y}-\mathrm{TZP}+0.1-3 \mathrm{~mol} \% \mathrm{CuO}\end{array}$ & $\begin{array}{l}\text { none } \\
\text { glass } \\
\text { glass }\end{array}$ & $\begin{array}{c}0.3-1 \\
0.4 \\
0.3-0.4\end{array}$ & $\begin{array}{c}1400 \\
1400 \\
1100-1250\end{array}$ & $\begin{array}{c}1-2 \\
1-1.4 \\
1.2-2 \\
\end{array}$ & $\begin{array}{c}620 \\
580 \\
230-450 \\
\end{array}$ \\
\hline & $\mathrm{ZrO}_{2} / 2.5 \mathrm{~mol}^{2} \mathrm{Y}_{2} \mathrm{O}_{3}$ /various $\mathrm{SiO}_{2}$-glass & & $1-3$ & $1000-1500$ & $1.6-2$ & $390-650$ \\
\hline \multirow[t]{2}{*}{ [19] } & $\begin{array}{l}\mathrm{ZrO}_{2} / 3 \mathrm{~mol} \% \mathrm{Y}_{2} \mathrm{O}_{3}(3 \mathrm{Y}-\mathrm{TZP}) \\
3 \mathrm{Y}-\mathrm{TZP}+\mathrm{Ba}-\mathrm{SiO}_{2} \text {-glass } \\
\end{array}$ & none or glass & $\begin{array}{c}0.2-0.5 \\
0.4 \\
\end{array}$ & $\begin{array}{l}1220-1330 \\
1200-1300 \\
\end{array}$ & $\begin{array}{l}1.1-2.7 \\
1.4-2.1 \\
\end{array}$ & $\begin{array}{c}570 \\
510-640 \\
\end{array}$ \\
\hline & $3 \mathrm{Y}-\mathrm{TZP} / 20 \mathrm{wt} \% \mathrm{Al}_{2} \mathrm{O}_{3}$ & none & 0.5 & $1200-1650$ & $1.5-2$ & $260-600$ \\
\hline \multirow[t]{2}{*}{ [20-21] } & $\mathrm{Al}_{2} \mathrm{O}_{3}(99.99 \%$ pure $)$ & & 0.9 & $1300-1400$ & & \\
\hline & $\mathrm{Al}_{2} \mathrm{O}_{3} / 200-1000 \mathrm{ppm} \mathrm{MgO}$ & & $0.5-3.3$ & $1300-1450$ & 2 & $520-550$ \\
\hline [17] & $\mathrm{Al}_{2} \mathrm{O}_{3} / 500 \mathrm{ppmMgO} / 500-1500 \mathrm{ppm}_{2} \mathrm{O}_{3}$ & Y segr./YAG & $0.6-2.3$ & $1450-1500$ & $1-2$ & $600-860$ \\
\hline \multirow[t]{8}{*}{ [22] } & $\mathrm{Al}_{2} \mathrm{O}_{3} / 500 \mathrm{ppm} \mathrm{MgO} / 1 \mathrm{wt} \% \mathrm{Cr}_{2} \mathrm{O}_{3}$ & & 1 & $1450-1500$ & $1-2$ & \\
\hline & $\mathrm{Al}_{2} \mathrm{O}_{3} / \mathrm{TiO}_{2}$ & & $0.8-1$ & $950-1000$ & 1,3 & \\
\hline & $\mathrm{Al}_{2} \mathrm{O}_{3} / 200 \mathrm{ppm} \mathrm{MgO} / 10 \mathrm{vol} \% \mathrm{ZrO}_{2}$ & & 0.5 & $1400-1450$ & 2 & \\
\hline & $\mathrm{Al}_{2} \mathrm{O}_{3} / 30 \mathrm{wt} \% \mathrm{TiC}$ & & 1.2 & $1300-1550$ & $3-4$ & 853 \\
\hline & $\mathrm{MgO} / 0.5 \% \mathrm{Fe}$ & pores & $0.1-1$ & $700-1050$ & 1 & $150-380$ \\
\hline & $\mathrm{UO}_{2}$ & pores & 2 & $1000-1600$ & $1-2$ & 250 \\
\hline & $\mathrm{TiO}_{2}$ & & $0.8-1$ & $950-1000$ & 1.3 & \\
\hline & $\mathrm{BaTiO}_{3}$ & & 0.45 & $1150-1250$ & $2-3$ & $800-1200$ \\
\hline $17,19,23-30,33$ & $\mathrm{Si}_{3} \mathrm{~N}_{4} /\left(\mathrm{MgO}\right.$ or $\left.\mathrm{Y}_{2} \mathrm{O}_{3}\right) / \mathrm{Al}_{2} \mathrm{O}_{3} /(\mathrm{AlN})$ & glass & $0.35-1$ & $1250-1580$ & $1-2$ & $540-940$ \\
\hline [34-35] & $\left(\alpha^{\prime}-Y_{\text {Sialon }}\right)_{x}\left(\beta^{\prime}-\text { Sialon }\right)_{y}\left(Y_{A G}\right)_{l_{x-y}}$ & glass & $\approx 0.2$ & $1500-1575$ & $0.5-1$ & \\
\hline \multirow[t]{4}{*}[36]{} & $\mathrm{Si}_{3} \mathrm{~N}_{4} / 20$ or $33 \mathrm{wt} \% \mathrm{SiC}+\mathrm{Y}_{2} \mathrm{O}_{3}+\mathrm{Al}_{2} \mathrm{O}_{3}$ & YSialon-glass & $0.2-1$ & $1550-1650$ & $1.5-2.3$ & \\
\hline & B-spodumene glass-ceramic & glass-matrix & $1-2$ & $1050-1150$ & $0.9-2$ & $630-710$ \\
\hline & $\alpha-\mathrm{SiC} / 0.3 \mathrm{wt} \% \mathrm{Al}$ & $\mathrm{Al}$ & $1.5-2.8$ & $1900-2060$ & $1-1.8$ & 630 \\
\hline & $\mathrm{Ca}_{10}\left(\mathrm{PO}_{4}\right)_{6}(\mathrm{OH})_{2}$ (hydroxyapatite) & & 0.64 & $1000-1100$ & $3-5$ & $>500$ \\
\hline
\end{tabular}

In metals, creep is often interpreted as being due to the collective motion of dislocations which are very mobile at high temperature and which can give rise to anelastic phenomena which are not directly related to the grain boundaries [37]. In fine-grained ceramics, on the contrary, due to the low density of intragranular dislocations combined with their low mobility at the usually achieved temperatures, creep takes place predominantly by GB-sliding. Therefore, fine-grained ceramics could turn out as model systems for the investigation of GB-relaxation peaks and give thus information on the glide and climb of GB-dislocations. This could bring new light in the controversy about the existence of a "grain boundary relaxation peak", genuinely produced by the mecanism of GB-sliding, which is still unresolved in metals [38]. Moreover, when amorphous intergranular phases are present, which soften and melt at temperatures relatively low compared to the melting temperature of the ceramic, new phenomena are expected, related to lubricated sliding and to relaxation processes inside of the second phase, which are absent in metals.

Another feature commonly observed in the mechanical loss spectra of all materials is the "hightemperature exponential background" (on which the GB-peak, if any, is superposed). This increase of mechanical loss is stronger in polycrystals than in single crystals and in metals it seems to be due to dislocation damping, but the exact mechanisms are not yet understood. Therefore, the description of such backgrounds remains empirical, e.g. as proposed by Schoeck et al. [39], where $f$ is the frequency, $H$ the activation enthalpy and $\alpha<1$ a broadening factor:

$$
\mathrm{Q}^{-1}=\frac{\mathrm{A}}{[\mathrm{f} \cdot \exp (\mathrm{H} / \mathrm{kT})]^{\alpha}}
$$




\section{HIGH TEMPERATURE DAMPING IN FINE-GRAINED CERAMICS}

Although the potential of the mechanical spectroscopy technique for measuring GB-sliding rates in ceramics was already recognized and applied in 1976 [23], since then only few investigations on high temperature damping of ceramics have been reported [16-36]. Moreover, most of the reports are incomplete as regards systematic exploration of the dependence of damping on frequency, stress, deformation amplitude, thermal history and microstructural evolution. This lack of data arises mainly from experimental shortcomings: most measurements were conducted using free decay methods which offer only a limited frequency and stress domain; the necessary high temperatures pose problems with gripping of the samples and limit the choice of atmosphere; finally, often only incomplete knowledge of the microstructure is available.

In this section, we briefly summarize the published data available to date by classifying the materials into three categories, as to the content and morphology of intergranular second phase. To illustrate the typical features, we present some results which we obtained in three different ceramic systems: silicon nitride, zirconia and alumina. The measurements were conducted using a differential, inverted torsionpendulum working with forced vibrations. The basic details are described in [17,27]. This pendulum allows measurements of the mechanical loss and of the elastic torsion modulus as a function of frequency (range $\left.10^{-4}-10 \mathrm{~Hz}\right)$, of temperature $(300-1600 \mathrm{~K})$ and of stress-amplitude $(\leq 12 \mathrm{MPa})$ in vacuum $\left(10^{-5} \mathrm{Torr}\right)$.

\subsection{Ceramics with a bulk secondary amorphous phase. Example: $\mathrm{Si}_{3} \mathrm{~N}_{4}$}

The internal friction measurements reported on silicon nitride and its composites show a large disparity [17, $19,24-36]$, due to the very sensitive dependence of the mechanical loss spectrum on the chemistry and crystalline state of the intergranular phase, which is unavoidable in these materials even when no sintering aids are used. Two main features appear: 1) In many cases, a well resolved peak at 1100-1450K, of height $5-150 \cdot 10^{-3}$, with activation enthalpy $340-1120 \mathrm{~kJ} / \mathrm{mol}$, which often evolves or even disappears with thermal treatments. 2) In all cases, an exponential background.

As an illustration, we show the typical spectrum obtained for a pressureless sintered $\mathrm{Si}_{3} \mathrm{~N}_{4}-10 \mathrm{wt} \%$ $\left(\mathrm{Y}_{2} \mathrm{O}_{3}-\mathrm{Al}_{2} \mathrm{O}_{3}-\mathrm{AlN}\right)$ material (Fig. 1). The observed peak $(1270 \mathrm{~K}, 1 \mathrm{~Hz})$ and associated modulus decrease $(15 \%)$ are manifestations of a relaxation phenomenon, as was shown by isothermal measurements [33].

The relaxation parameters (Fig. 2) are however unusual: activation enthalpy $=1117 \mathrm{~kJ} / \mathrm{mol}$, preexponential factor $=10^{47} \mathrm{~s}$. The peak disappears irreversibly on cooling and the spectrum stabilizes (for $\mathrm{T}<1600 \mathrm{~K}$ ) towards a diminished exponential background (Fig. 1) which has an activation enthalpy similar to the one of the peak $(1075 \mathrm{~kJ} / \mathrm{mol})$.

The evolution of the spectrum depends however strongly on the nature of second phases. In the case of a $\mathrm{Si}_{3} \mathrm{~N}_{4}-7.5 \mathrm{wt} \%\left(\mathrm{Y}_{2} \mathrm{O}_{3}-\mathrm{Al}_{2} \mathrm{O}_{3}\right)$ grade, the peak also at first disappears but heating up to $1600 \mathrm{~K}$ leads to its reappearance, although at lower height (Fig. 3). Moreover, here the background and its associated modulus decrease are both higher compared to the other grade. Finally, in a composite of $30 \mathrm{vol} \% \mathrm{TiN}-\mathrm{Si}_{3} \mathrm{~N}_{4}-7.5 \mathrm{wt} \%$ $\left(\mathrm{Y}_{2} \mathrm{O}_{3}-\mathrm{Al}_{2} \mathrm{O}_{3}\right)$, the peak never disappears completely [30] and at the same time the exponential background is much higher than in the corresponding matrix material (Fig. 4). It is worth mentioning that the creep resistance of these three grades decreases in the same order as their mechanical loss background becomes stronger, indicating that the background is due to viscoplastic deformation [31-32]. The occurence of this peak is related to the presence of bulk intergranular glass phase at the triple points. Effectively, after the peak had disappeared and the modulus increased (Fig. 3), it was confirmed by TEM observations that the glass-phase had crystallized [33]. In the case where the peak reappeared with lower intensity, the phase. was found to be partly amorphous, indicating that it must have partly melted above $1500 \mathrm{~K}$. We conclude that the addition of TiN particles impedes the crystallization of the intergranular glass phase.

It is then straightforward to attribute the observed peak to the glass phase, but what is the underlying mechanism? Knowing that the glass transition temperature, $\mathrm{T}_{\mathrm{g}}$, of YSiAlON glasses lies around $1200 \mathrm{~K}$ [40], it seems plausible to associate the peak to the $\alpha$-relaxation, which occurs in glasses at temperatures near $T_{g}$. In a pure anorganic glass, the quantity tan $\phi$ increases monotonically without a peak [41-42]. The appearance of a peak in our case points to the existence of a restoring force, probably given by the rigid skeleton of the surrounding $\mathrm{Si}_{3} \mathrm{~N}_{4}$ grains. In glasses and when big variations of the shear modulus $\mu$ are involved, the free activation energy $\Delta \mathrm{G}_{\text {act }}$ is not equal to the activation enthalpy $\Delta H$, because of the large entropic contribution. This can be accounted for by using the approach of Schoeck and Escaig [43-44], where the activation volume $\mathrm{V}$ is negligibly small in oxynitride glasses [40]:

$$
\Delta \mathrm{G}_{\mathrm{act}}=\frac{\Delta \mathrm{H}+\mathrm{T} / \mu \cdot \partial \mu / \partial \mathrm{T} \cdot \sigma \mathrm{V}}{1-\mathrm{T} / \mu \cdot \partial \mu / \partial \mathrm{T}}
$$



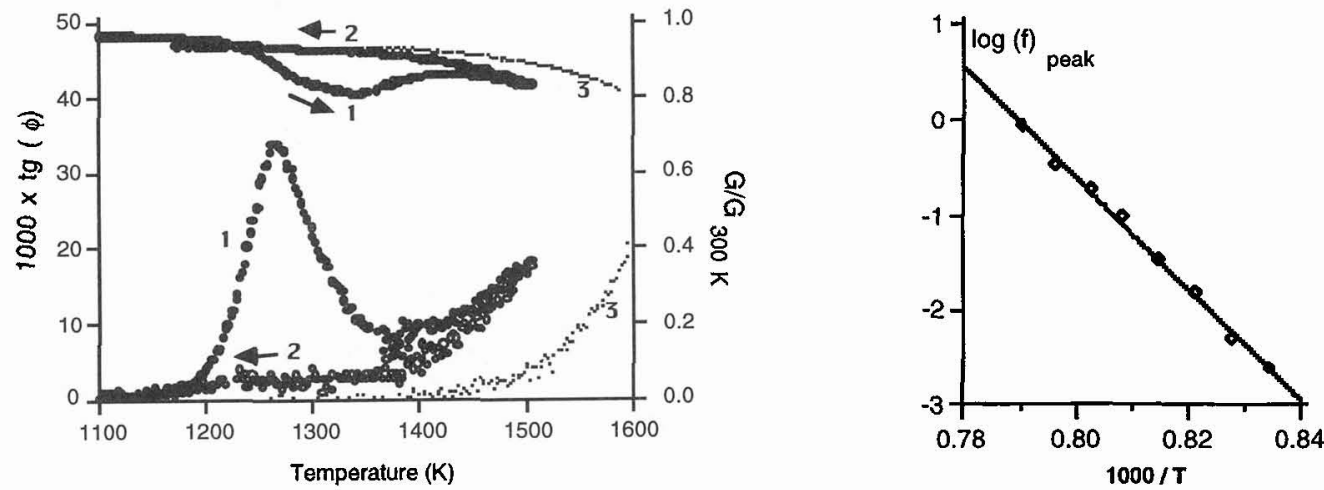

Figure 1: Evolution of mechanical loss and torsion modulus of $\mathrm{Si}_{3} \mathrm{~N}_{4}-10 \mathrm{wt} \%\left(\mathrm{Y}_{2} \mathrm{O}_{3}-\mathrm{Al}_{2} \mathrm{O}_{3}-\mathrm{AlN}\right), \mathrm{f}=1 \mathrm{~Hz}, \dot{\mathrm{T}}=1 \mathrm{~K} / \mathrm{min}$.

(1) State as received, measurement on heating to $1500 \mathrm{~K}$.

(2) On cooling: disappearance of peak and modulus decrease.

(3) Stable background after repeated thermal cycling to $1600 \mathrm{~K}$.

Figure 2: Arrhenius plot obtained from the peak shift in isothermal measurements below $1270 \mathrm{~K}$ on same material as in Fig. 1. Deduced relaxation parameters:

$\mathrm{H}=1117( \pm 22) \mathrm{kJ} / \mathrm{mol}, \tau_{\mathrm{o}}=0.8 \cdot 10^{-47( \pm 2)} \mathrm{s}$.
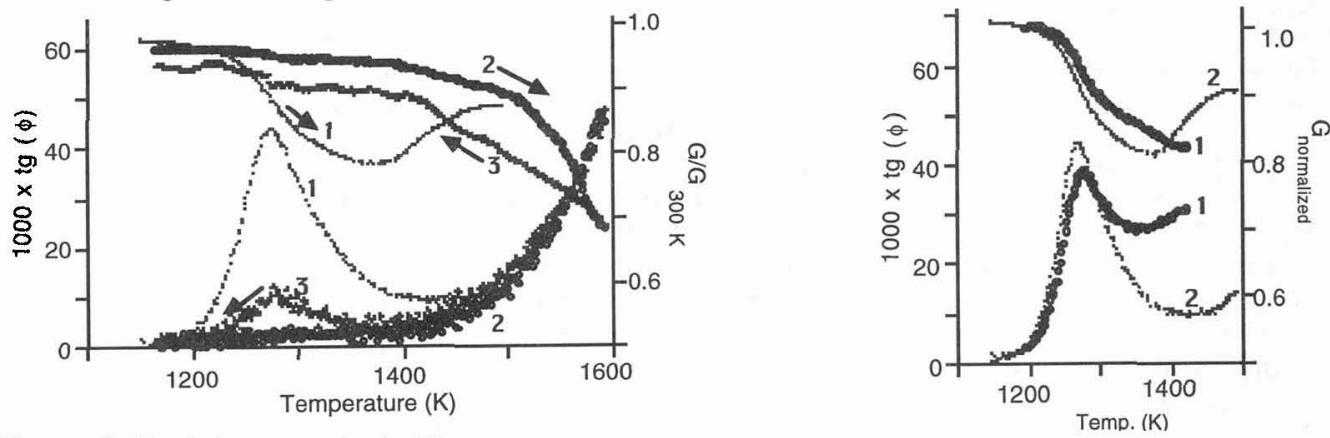

Figure 3: Evolution of mechanical loss and shear modulus of $\mathrm{Si}_{3} \mathrm{~N}_{4}-7.5 \mathrm{wt} \%\left(\mathrm{Y}_{2} \mathrm{O}_{3}-\mathrm{Al}_{2} \mathrm{O}_{3}\right), \mathrm{f}=1 \mathrm{~Hz}, \dot{\mathrm{T}}=1 \mathrm{~K} / \mathrm{min}$.

(1) State as received, measurement on heating to $1500 \mathrm{~K}$.

(2) Disappearance of the peak after repeated thermal cycling up to $1500 \mathrm{~K}$. First heating to $1600 \mathrm{~K}$.

(3) Reappearance of the peak on cooling from $1600 \mathrm{~K}$.

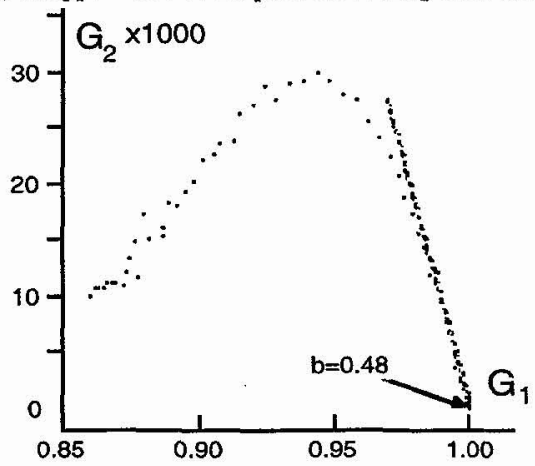

Figure 5: Cole-Cole diagram (imaginary vs. real part of the dynamical modulus) of the master curves from isothermal measurements on $\mathrm{Si}_{3} \mathrm{~N}_{4}-10 \mathrm{wt} \%\left(\mathrm{Y}_{2} \mathrm{O}_{3}-\mathrm{Al}_{2} \mathrm{O}_{3}-\mathrm{AlN}\right)$.

Figure 4: Mechanical loss of a composite $30 \mathrm{vol} \%$ TiN$\mathrm{Si}_{3} \mathrm{~N}_{4}-7.5 \mathrm{wt} \%\left(\mathrm{Y}_{2} \mathrm{O}_{3}-\mathrm{Al}_{2} \mathrm{O}_{3}\right)$ (1) compared to its matrix (2). The mechanical loss background of the composite is higher and the associated modulus decrease is not followed by a reincrease. The peak does not disappear.

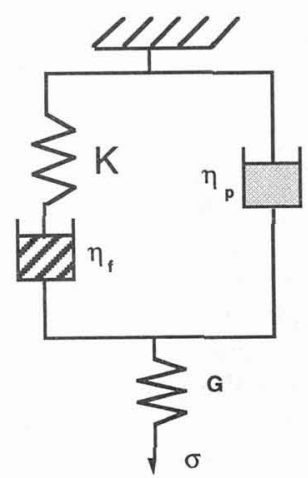

Figure 6: Rheological model describing the anelastic and viscoplastic deformation of $\mathrm{Si}_{3} \mathbf{N}_{4}$. Dashpots represent viscous friction forces, referring to pockets of glass phase $\left(\eta_{p}\right)$ and to thin films $\left(\eta_{t}\right)$, while springs represent elastic restoring forces. 
In the present case, taking the modulus variation as measured by ultrasonic techniques in [40], Eq. (2) yields a reasonable free activation energy value of $\approx 500-700 \mathrm{~kJ} / \mathrm{mol}$ in the peak temperature range. This supports the interpretation of the peak as being due to the $\alpha$-relaxation in the glassy phase. Therefore, $\tan \phi$ is not a relevant quantity and it is preferable to refer to the real and imaginary part of the modulus which, when reported in a Cole-Cole plot (Fig. 5), can provide additional information as to the degree of correlation which characterizes the atomic mobility in the glass [45]. From the slope of $G_{2}$ vs. $G_{1}$ at high frequency, we obtain a correlation factor $b=0.48$, which is typical of other oxynitride glasses as well [42]. Then the activation energy of the elementary process ( $\beta$-relaxation) is obtained as $\mathrm{H}_{\beta}=\mathrm{H} \cdot \mathrm{b}=536 \mathrm{~kJ} / \mathrm{mol}$, which is of the order of the free activation energy for creep in YSiAlON glasses $(400-600 \mathrm{~kJ} / \mathrm{mol})[40]$.

On the basis of all these observations, the spectrum was interpreted by using a rheological model (Fig. 6) accounting for the coupled anelastic and viscoplastic relaxation phenomena (peak and background). The dashpots represent the viscosities of bulk pockets and thin films of glass respectively, while the springs stand for the elastic restoring forces. Note finally that the spectra of silicon nitrides show similarities to the spectum of WC-11wt\%Co [46] where also a peak and a background are obtained and the peak has its origin in a mechanism (dislocation motion) taking place inside of the bulk regions of cobalt binder phase. Here as well, abnormally high values of the activation enthalpy and of the preexponential attempt frequency term are obtained, which stem from an evolution of the material during the measurement [46].

\subsection{Ceramics containing thin amorphous GB-layers. Example: $\mathrm{ZrO}_{2}$}

Only very few investigations of the mechanical loss at high temperature are available in zirconia [16-19]. Our measurements on fine-grained $(0.3-1 \mu \mathrm{m}) \mathrm{ZrO}_{2}-2 \mathrm{~mol}_{2} \mathrm{Y}_{2} \mathrm{O}_{3}(2 \mathrm{Y}-\mathrm{TZP})$ show a monotonic increase of damping together with an abrupt decrease of the modulus above $1200 \mathrm{~K}$ (Fig. 7). These are manifestations of a relaxation process, as isothermal measurements at temperatures up to $1600 \mathrm{~K}$ at frequencies between $10^{-4}$ and $10 \mathrm{~Hz}$ have shown (Fig. 8). From these, it also becomes clear that the spectra consist of a highfrequency part ("peak") and a low frequency part ("background").

Figure 7 shows how the damping and modulus decrease depend on the impurity content: both are higher in a grade containing $910 \mathrm{ppm} \mathrm{SiO}_{2}$ plus other impurities (forming thin intergranular glassy layers), as compared to a purer grade with $<20 \mathrm{ppm} \mathrm{SiO}_{2}$ (with no detectable glass-phase). This bears qualitative analogy to the creep resistance of these materials which is inferior in the less pure grade, a fact which was attributed to the lubricating effect of the glassy layers on GB-sliding [47-48]. The activation enthalpy values obtained from the shift of the high-frequency part of the spectra are 590 and $630 \mathrm{~kJ} / \mathrm{mol}$ respectively, values which are close to the ones obtained from creep tests $(580$ and $620 \mathrm{~kJ} / \mathrm{mol} \mathrm{resp}$.). Finally, in the purer grade, the mechanical loss was observed to vary in inverse proportion to the grain size (Fig. 9), again similar to the creep behaviour where also a grain size exponent equal to one is obtained [47-48].

This close relation between damping and creep deformation points to a common mechanism operating in both experimental conditions and suggests that the damping is directly associated with microplastic deformation. Therefore, we attempted to interprete the mechanical loss spectra by using a simple GB-sliding model (Fig. 10) of grains separated by a GB-layer of thickness $\delta$ and viscosity $\eta$ (representing either the viscosity of the silica-based glass or the intrinsic GB-viscosity, in the "purer" grade). By using Newton's law, we thus calculate the predicted mechanical loss:

$$
\sigma_{\mathrm{xy}}=\frac{\eta}{\delta} \dot{\mathrm{x}}+\mathrm{Kx} \Rightarrow \tan \phi=\frac{\mathrm{G}}{\mathrm{d}} \cdot \frac{\omega \eta / \delta}{\left(\mathrm{KG} / \mathrm{d}+\mathrm{K}^{2}\right)+(\omega \eta / \delta)^{2}}
$$

The shape of the spectrum will depend on the restoring force constant $\mathrm{K}$, which represents the limitation of the GB-sliding due to the rigidity of the polycrystal. If $\mathrm{K}$ is strong, one obtains a peak, if it vanishes, a background (steady increase). Since $\mathrm{K}$ represents the rigidity of the material, it is expected to decrease in the same measure as microplastic deformation becomes important, i.e. at long times (low frequency) and high temperatures. Such a variation of $\mathrm{K}$ effectively leads to a calculated spectrum which is qualitatively similar to the experimental one (Fig. 8) [17-18]. We therefore believe that the measured spectra in zirconia should not be separated into independent peak and background components, as would be the classical way of proceeding, but that they are better described by a model as above. The transition between the high and low frequency parts of the spectrum is thus related to the oncet of microplasticity. Such a transition should also appear as a function of temperature, provided measurements at high enough temperatures are possible.

\subsection{Ceramics with glass-free grain boundaries. Example: $\mathrm{Al}_{2} \mathrm{O}_{3}$}

Again, only very few measurements have been reported on alumina $[17,18,20-22]$. The spectrum shows close similarity to the one of zirconia: in measurements as a function of temperature, a monotonic increase of damping is observed, accompanied by a decrease in modulus, as illustrated in Fig. 11 for a $\mathrm{Al}_{2} \mathrm{O}_{3}$. 


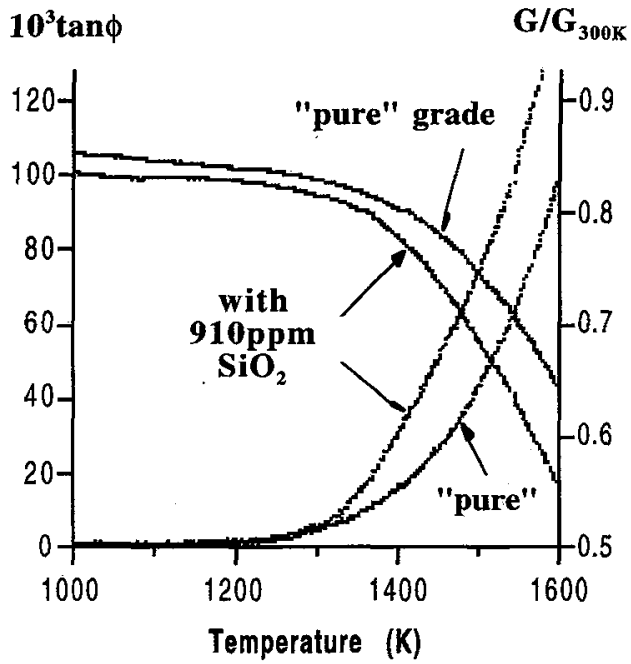

Figure 7: Influence of impurity content on the hightemperature mechanical loss and modulus decrease in $\mathrm{ZrO}_{2}$ $2 \mathrm{~mol} \% \mathrm{Y}_{2} \mathrm{O}_{3}, \mathrm{f}=1 \mathrm{~Hz}, \dot{\mathrm{T}}=1 \mathrm{~K} / \mathrm{min}$.

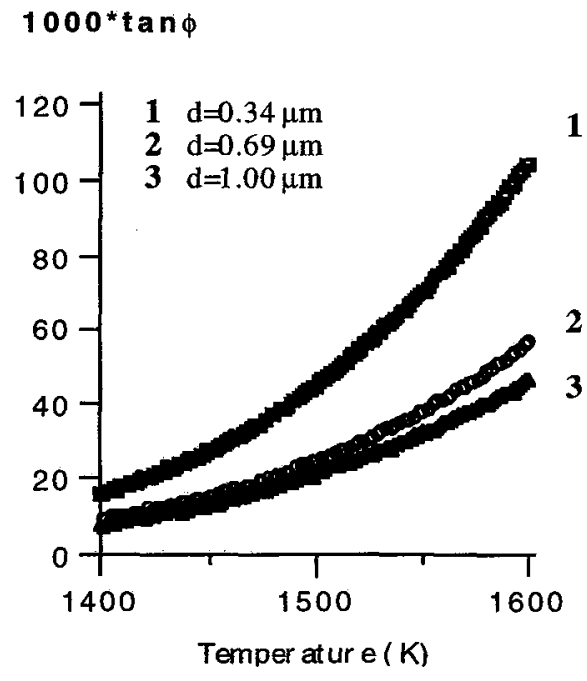

Figure 9: Dependence of the mechanical loss on the grain size $d$ (roughly $1 / d$ ) in "pure" $\mathrm{ZrO}_{2}-2 \mathrm{~mol}_{2} \mathrm{Y}_{2} \mathrm{O}_{3}$ at $\mathrm{f}=1 \mathrm{~Hz}$.

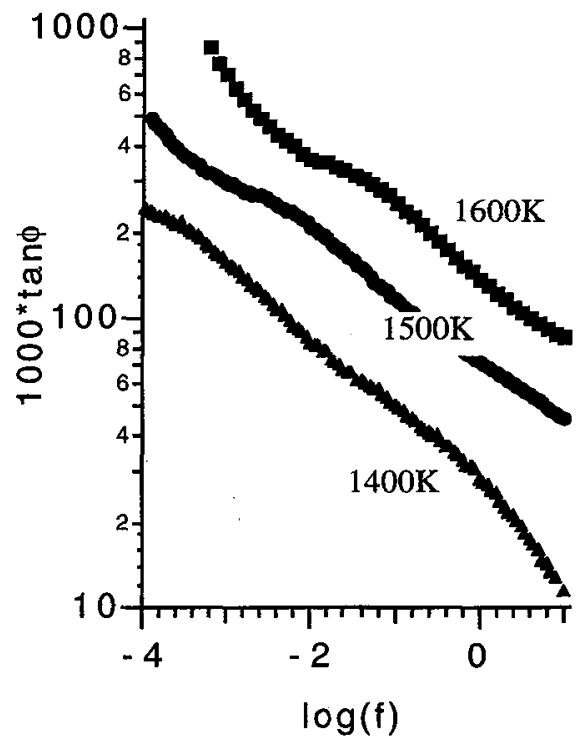

Figure 8: Isothermal spectra in "impure" $0,4 \mu \mathrm{m}$-grain $\mathrm{ZrO}_{2}$ $2 \mathrm{~mol} \% \mathrm{Y}_{2} \mathrm{O}_{3}$. Together with isochronal measurements one obtains $H=586 \mathrm{~kJ} / \mathrm{mol}$ from the spectrum shift at $\tan \phi=0.15$.
Figure 10: Model of hexagonal grains (size d), separated by an intergranular layer of thickness $\delta$ and viscosity $\eta$. Sliding $(x)$ occurs under the effect of the applied shear stress $\left(\sigma_{\mathrm{xy}}\right)$. 
$500 \mathrm{ppm} \mathrm{MgO}$ grade. Again, isothermal measurements reveal that these phenomena are the high-frequency part of a spectrum (Fig. 12) which, at lower frequency turns into a steady increase of mechanical loss (background). Fig. 12 shows a "master spectrum", meaning a superposition of spectra taken at different temperatures $(1350-1550 \mathrm{~K})$ by shifting them along the "logf-axis". The fact that it is possible to superpose the spectra by this way shows that the spectrum can be described by a single activation enthalpy value, namely $840 \mathrm{~kJ} / \mathrm{mol}$, indicating that a single mechanism is probably at the origin of the entire spectrum. This value is however higher than the one obtained by creep tests on identical specimens [49-50].

Moreover, we investigated the effect of the amplitude of the applied stress in the range 3-12MPa. The measurements revealed a threshold-type dependence of damping at about $2 \mathrm{MPa}$, increasingly pronounced at lower frequencies (Fig. 13). This could be due either to an additional relaxation process, activated above a certain stress level or due to a stress-dependence of the main mechanism which gives rise to the basic spectrum. We tend to favour the second version because the stress-dependence becomes prominent for the same low frequencies were the transition between "peak"- and "background"-type behaviour takes place which, as in the case of zirconia, could be related with a diminution of the restoring force. Finally, we were able to explore the effect of grain size $(0.7-3.3 \mu \mathrm{m})$ and amount of $\mathrm{Y}_{2} \mathrm{O}_{3}$-codoping $(0,500,1500 \mathrm{ppm})$ on the spectra (Fig. 14) which all showed remarkable reproducibility from sample to sample, from measurement to measurement and stability even for long measurement times (several days).

The influence of the microstructural parameters seems at first sight quite complex but is actually in very good qualitative analogy with the creep behaviour, if in Fig. 14 we substitute the mechanical loss by the creep rate at $20 \mathrm{MPa}, 1723 \mathrm{~K}$, on identical specimens [50]. This fact shows that there is a close correlation between creep deformation and anelastic deformation. However, the activation enthalply values as derived from mechanical spectroscopy $(840-1075 \mathrm{~kJ} / \mathrm{mol})$ are consistently higher that those from creep $(520-800 \mathrm{~kJ} / \mathrm{mol})$, contrary to the case of zirconia where identical values were obtained.

Such a complicated influence of the grain size and dopant content as in Fig. 14 cannot be explained by a simple model as the one in Fig. 10. Effectively, when the GBs are devoid of glassy phase, as was the case with the alumina ceramics presented here, a model taking into account the microstructural aspects of GB-sliding in terms of glide and climb of GB-dislocations is more appropriate. In this model, there are three important parameters controlling the damping: 1) the density $\Lambda$ of GB-dislocations, which is inversely proportional to the grain size, 2) their mobility $B_{1}^{-1}$, depending on jog creation and migration and 3 ) the restoring force $\mathrm{K}$. By taking into account the information on the segregation of $\mathrm{Y}$-atoms to the GBs and the precipitation of YAG particles [50], such a model permits to discuss qualitatively the result of Fig. 14 [17]. Moreover, it is possible to describe the transition from peak to background (Fig. 12) by postulating that the pinning points of the vibrating dislocation segments are not immobile but can themselves move with a mobility $B_{2}^{-1}$ [51]. Therefore, instead of Eq. (3), a system of equations is needed, like Eq. (4) where $x$ and u stand for the average positions of the dislocation and of its pinning points, respectively. The predicted spectrum has the form of a peak at high frequency with a transition to a monotonic backgound in the low frequency limit:

$$
\begin{aligned}
& \sigma b=B_{1} \dot{x}+K(x-u) \\
& B_{2} \dot{u}=K(x-u)
\end{aligned} \quad \Rightarrow \quad \tan \phi=\frac{\frac{\Lambda b^{2}}{B_{2}}\left(1+\frac{B_{1}}{B_{2}}\right)+\frac{\Lambda b^{2} B_{1}}{K^{2}} \omega^{2}}{\omega\left[\frac{1}{G_{U}}\left(1+\frac{B_{1}}{B_{2}}\right)^{2}+\frac{\Lambda b^{2}}{K}+\frac{B_{1}^{2}}{G_{U} K^{2}} \omega^{2}\right]}
$$

( $\omega$ ist the angular frequency, $b$ the Burgers vector and $\mathrm{G}_{U}$ the unrelaxed shear modulus). Interestingly, Eqs. (4) correspond to a 4-parameter rheological model identical to Fig. 6, if the viscosities are replaced by the two friction terms $B_{1}$ and $B_{2}$.

\section{CONCLUSIONS, SUGGESTIONS FOR FURTHER RESEARCH}

The high temperature spectra of three types of fine-grained ceramics were investigated. They all are composed of a mechanical loss peak which is superimposed on a mechanical loss background and accompanied by a decrease in the torsion modulus. In all cases the magnitude of damping can be directly correlated to the creep rate measured on identical material. The analysis of the spectra permits to distinguish between the contribution to the anelastic deformation of three different types of microstructural elements frequently encountered in ceramics: 1) Triple points containing bulk regions of amorphous intergranular phase. A well resolved mechanical loss peak is observed which has its origin in this bulk phase and appears above its glass transition temperature. The evolution of the peak height permits to follow the crystallization 


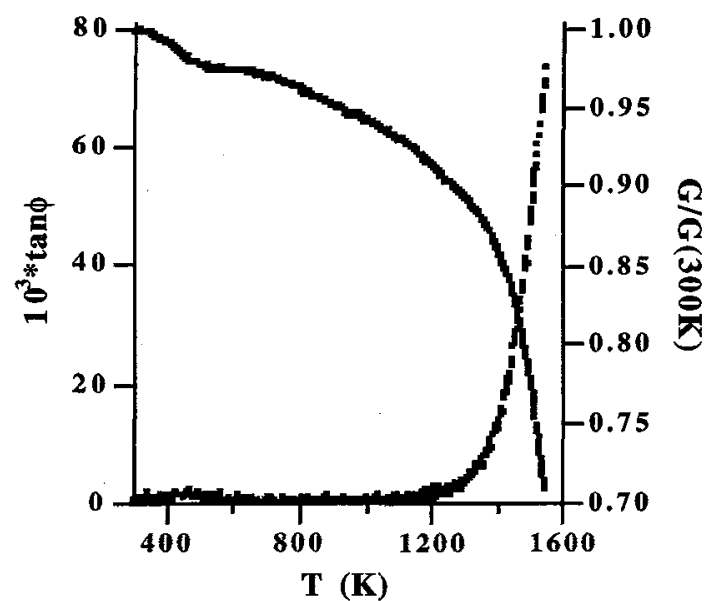

Figure 11: Temperature dependence of the mechanical loss and torsion modulus in $\mathrm{Al}_{2} \mathrm{O}_{3}-500 \mathrm{ppmMgO}$. $\mathrm{f}=1 \mathrm{~Hz}, \dot{\mathrm{T}}=1 \mathrm{~K} / \mathrm{min}$.

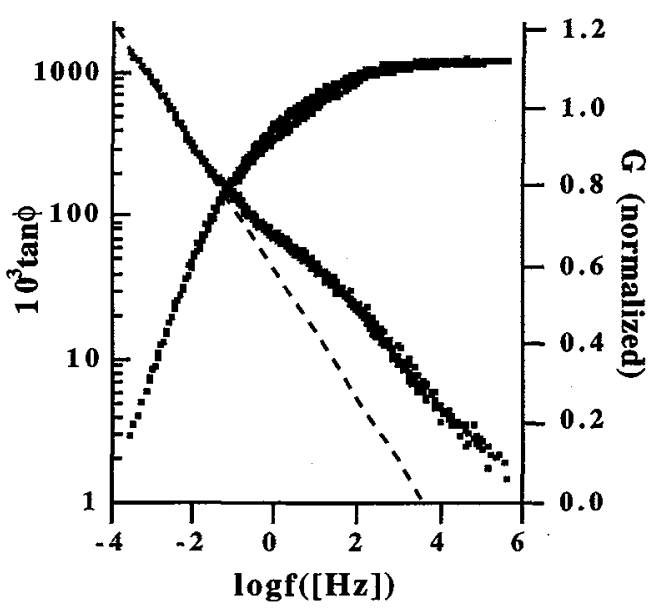

Figure 12: Frequency dependence of the mechanical loss and modulus in $\mathrm{Al}_{2} \mathrm{O}_{3}-500$ ppmMgO: "master-curve" obtained by superposition of several spectra at $1350-1550 \mathrm{~K} . \mathrm{H}=884 \mathrm{~kJ} / \mathrm{mol}$

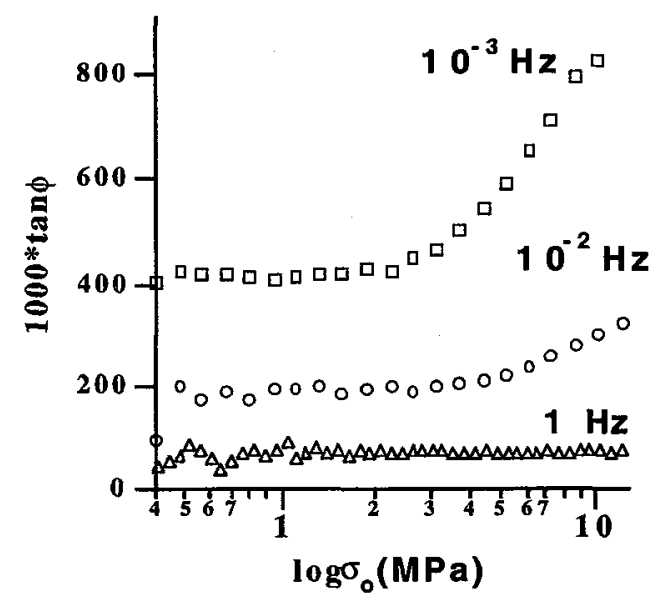

Figure 13: Dependence of the mechanical loss in $\mathrm{Al}_{2} \mathrm{O}_{3}$ $500 \mathrm{ppmMgO}$ at $1550 \mathrm{~K}$ on the applied stress-amplitude. Threshold-type behaviour for low frequency $\left(10^{-3} \mathrm{~Hz}\right)$.

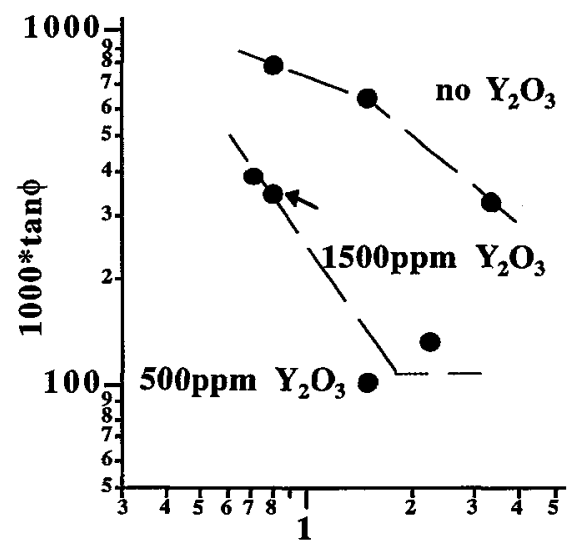

d $[\mu \mathrm{m}]$

Figure 14: Influence of microstructural parameters (content of $\mathrm{Y}_{2} \mathrm{O}_{3}$-codoping and grain size d) on the mechanical loss at $\mathrm{f}=1 \mathrm{mHz}, \mathrm{T}=1550 \mathrm{~K}$. 
or reamorphization of this phase during heat treatments. 2) Grain boundaries containing a thin amorphous film (oxide or oxynitride glass in this case). GB-sliding is lubricated by the presence of this second phase, whose viscosity may thus be estimated on the basis of mechanical loss measurements. 3) Grain boundaries devoid of glassy phase. The intrinsic properties of the boundary determine the anelastic deformation, i.e. the anelastic behavior is best described in terms of GB-dislocation motion. This can be affected by the segregation of dopant elements or precipitation of second phase particles.

A common feature that appears in all high temperature measurements is the exponential increase of damping, which is accompanied with a steady decrease of the dynamical modulus. This (viscoelastic) "damping background", which is intimately related with microplastic deformation, is however poorely investigated and its mechanisms not understood. Except of the empirical relation of Eq. (1), no quantitative description of the background is yet established. Moreover, with spectra like the ones of zirconia and alumina, it seems that peak and background are related and depend on the same mechanism. In that case, approaches as in Eqs. (3) and (4) could provide a description of the measured spectra, however, too many parameters are open, like the restoring force and mobility terms, so that such an approach remains at present qualitative. Finally, the experimentally observed broadening of the spectra (factor $\alpha=2-4$ in Figs. 8 and 12) further hinders any quantitative interpretation in terms of micromechanisms.

We only begin to understand the micromechanisms involved in the anelastic and microplastic deformation of ceramics. Only few materials have been investigated yet, while there remains a long list of systems where (super)plastic deformation has been achieved (Table 1). Given the strong influence of even small microstructural changes, it is thereby extremely important to characterize the materials as precisely as possible and to preferably combine different techniques (mechanical spectroscopy, creep tests, microscopy observations) on identical material grades. Moreover, in cases where the structure evolves (grain growth, crystallization, segregation/precipitation, redistribution of the glassy phase from GBs to triple points) the thermal history of the samples should be well defined. In that case, mechanical spectroscopy can provide a powerful tool to detect such evolutions.

Another open question is the interpretation of the activation enthalpy values obtained by the shift method. They are always higher than the self-diffusion values and often higher than the creep activation values as well. While the approach by Perez and coworkers [45] can be applied to the case where glasses are involved, the correct interpretation of the activation enthalpies in all other cases is still open.

By the nature of the technique, mechanical loss measurements take place at temperatures and stresses which are lower than those achieved in creep tests. Therefore, at most only "microplastic" deformation is achieved, which is controlled by the "interface reaction" process [14-15] which depends either on the transfer of matter through the glassy phase or on the mobility of GB-dislocations. These phenomena are important for understanding threshold stress behaviors and predicting creep of materials at low stress and temperature, where a creep test would take too much time because of the low macroscopic creep rate.

Isothermal measurements with forced vibrations which offer both a large frequency domain and a constant microstructure are preferable over free decay methods, especially given the large variations of modulus and the microstructural evolutions. Also, if possible, stress-amplitude effects should be investigated at stresses that come as close as possible to the creep testing conditions. At the same time, it is valuable to measure and report the absolute values of the dynamic elastic modulus, whose variations can also provide complementary information, e.g. when second phases soften or when porosity is present.

\section{Acknowledgements}

The authors wish to express their gratitude to C. Carry, R. Duclos, M. Nauer and G. Bernard-Granger for supplying the specimens, for valuable informations about microstructure and creep deformation and for many helpful discussions. This work was financially supported by the Swiss National Science Foundation.

\section{References}

[1] Carry C. and Mocellin, A. "High ductilities in fine grained ceramics", Superplasticity, M. Baudelet and M. Suéry Eds. (Editions du CNRS, France, 1985) pp. 16.11-16.19.

[2] Carry C., "High ductilities, superplastic behaviors and associated mechanisms in fine grained ceramis", Int. Mtg. on Adv. Mats., M. Kobayashi and F. Wakai Eds. (MRS, 1989) pp.199-215.

[3] Wakai F., Br. Ceram. Trans. J. 88 (1989) pp. 205-208.

[4] Chen I. W. Xue L. A., J. Am. Ceram. Soc. 73 (1990) pp. 2585-2609.

[5] Maehara Y., Langdon T. G., J. Mater. Sci. 25 (1990) pp. 2275-2286.

[6] Kim W. J., Wolfenstine J., Sherby O. D., Acta Metall. Mater. 39 (1991) pp. 199-208.

[7] Wakai F., Ceramics International 17 (1991) pp. 153-163.

[8] Chokshi A. H., Mater. Sci. Eng. A166 (1993) pp. 119-133. 
[9] Nieh T. G., Wadsworth J., Mater. Sci. Forum 170-172 (1994) pp. 359-368.

[10] Sakuma T., Yoshizawa Y. I., Mater. Sci. Forum 170-172 (1994) pp. 369-378.

[11] Sherby O. D., Nieh T. G., Wadsworth J., Mater. Sci. Forum 170-172 (1994) pp. 13-22.

[12] Clarke D., J. Am. Ceram. Soc. 70 (1987) pp. 15-22.

[13] Raj R., J. Am. Ceram. Soc. 64 (1981) pp. 245-248.

[14] Arzt E., Ashby M. F., Verrall R. A., Acta Metall. 31 (1983) pp. 1977-1989.

[15] Raj R., Chyung C. K., Acta Metall. 29 (1981) pp. 159-166.

[16] Lakki A., Schaller R., Nauer M. and Carry C., Acta Metall. Mater. 41 (1993) pp. 2845-2853.

[17] Lakki A., Mechanical spectroscopy of fine-grained zirconia, alumina and silicon nitride ( $\mathrm{PhD}$-thesis, EPFL, Lausanne, 1994).

[18] Lakki A., Schaller R., "Damping due to grain boundary sliding in zirconia and alumina", to appear in: Inter. Symp. on M3D III: Mechanics and mechanisms of material damping, Norfolk, Virginia, 1995, V. K. Kinra and A. Wolfenden Eds. (ASTM STP 1304)

[19] Nishiyama K., Yamanaka M., Omori M., Umekawa S., J. Mater. Sci. Lett. 9 (1990) pp. 526-528.

[20] Sakaguchi S., Murayama N., Kodama Y., Wakai F., J. Alloys and Compounds 211/212 (1994) pp. 361-364.

[21] Kumazawa T., Ohta S., Kanzaki S., Sakaguchi S., Tabata H., J. Mater. Sci. Lett. 8 (1989) pp. 47 48.

[22] Ota K., Pezzotti G., Scripta Metall. Mater. 34 (1996) pp. 1467-1472.

[23] Mosher D. R., Raj R., Kossowsky R., J. Mater. Sci. 11 (1976) pp. 49-53.

[24] Tsai R. L., Raj R., J. Am. Ceram. Soc. 63 (1980) pp. 513-517.

[25] Sakaguchi S., Murayama N., Wakai F., J. Ceram. Soc. Jpn. Int. Ed. 95 (1987) pp. 1162-1165.

[26] Shiori J., Furuta O. and Satoh K., in: Nondestructive Characterization of Materials II Bussière Ed. (Plenum Press, 1987) pp. 325-333.

[27] Gadaud P., Guisolan B., Kulik A., Schaller R., Rev. Sci. Instrum. 61 (1990) pp. 2671-2675.

[28] Pezzotti G., Tanaka I., Okamoto T., J. Am. Ceram. Soc. 74 (1991) pp. 326-332.

[29] Tanaka I., Pezzotti G., Matsushita K., Miyamoto Z., Okamoto T., J. Am. Ceram. Soc. 74 (1991) pp. $752-759$.

[30] Lakki A., Schaller R., "High temperature behaviour of TiN-reinforced silicon nitride studied by mechanical spectroscopy"1, 13th Ris $\emptyset$ Int. Symp. on Mater. Sci., Roskilde (DK), 1991, S. I. Andersen et al. Eds. (Ris $\emptyset$ Nat. Lab., Roskilde, 1992) pp.311-316.

[31] Crampon J., Duclos R., Acta Metall. Mater. 38 (1990) pp. 805-810.

[32] Bernard-Granger G., Dévitrification de la phase intergranulaire du nitrure de silicium. Influence sur les propriétés mécaniques à haute température (PhD-thesis, UST, Lille, 1994).

[33] Lakki A., Schaller R., Bernard-Granger G., Duclos R., Acta Metall. Mater. 43 (1995) pp. 419-426.

[34] Ota K., Pezzotti G., Phil. Mag. A 73 (1996) pp. 223-235.

[35] Watari K., Sakaguchi S., Kanzaki S., Hamazaki T., Ishizaki K., J. Mater. Res. 9 (1994) pp. 27412744.

[36] Pezzotti G., Ota K., Kleebe H.-J., Okamoto J., Nishida T., Acta Metall. Mater. 43 (1995) pp. 43574370.

[37] Woirgard J., Rivière A., Fouquet J., J. de Physique Colloque C5 (1981) pp. 407-419.

[38] Povolo F., Molinas B. J., Nuovo Cimento D 14 (1992) pp. 287-332.

[39] Schoeck G., Bisogni E., Shyne J., Acta Metall. 12 (1964) pp. 1466-1468.

[40] Rouxel T., Huger M., Besson J. L., J. Mater. Sci. 27 (1992) pp. 279-284.

[41] Sekkat A., Comportement micromécanique de systèmes vitreux de nature différente autour de la température de transition vitreuse: approche expérimentale et modélisation (PhD-thesis, INSA Lyon, 1992).

[42] Donzel L. and Schaller R., "Mechanical Spectroscopy of a YSiAlON glass", this conference.

[43] Escaig B. and Lefebvre J. M., Revue de Physique Appliquée 13 (1978) pp. 285-292.

[44] Schoeck G., Phys. Stat. Sol. 8 (1965) pp. 499-507.

[45] Perez J., Physique et mécanique des polymères amorphes (Lavoisier, Paris, 1992)

[46] Ammann J. J., Schaller R., J. Alloys Compounds 211/212 (1994) pp. 397-401.

[47] Nauer M., Carry C., Scripta Metall. Mater. 24 (1990) pp. 1459-1463.

[48] Nauer M., Microstructure et plasticité de zircones yttriées (PhD-thesis, EPFL, Lausanne, 1992).

[49] Gruffel P. , Carry C., "Strain rate plateau in creep of yttria doped fine grained alumina", 11th Ris $\emptyset$ Inter. Symp. on Metallurgy and Mater. Sci.: Structural Ceramics-Processing, Microstructure and Properties, Roskilde, DK, J. J. Bentzen et al. Eds. (Risø Nat. Lab., Roskilde,1990) pp.305-311.

[50] Gruffel P., Evolutions structurales d'alumines à grains fins dopées à l'yttrium et fluage superplastique (PhD-thesis, EPFL, Lausanne, 1991).

[51] Lakki A, Schaller R., to be published 